\title{
Nanovectorized radiotherapy: a new strategy to induce anti-tumor immunity
}

\author{
Claire Vanpouille-Box ${ }^{1,2 \dagger}$ and François Hindrée, ${ }^{1,2 *}$ \\ ' LUNAM Université, Université d'Angers, Angers, France \\ 2 INSERM U1066 Micro et Nanomedecines Biomimétiques, Angers, France
}

\section{Edited by:}

Sandra Demaria, New York University School of Medicine, USA

\section{Reviewed by:}

Peter B. Schiff, New York University School of Medicine, USA

Pedro Francisco Escobar, Cleveland

Clinic Foundation, USA

\section{${ }^{*}$ Correspondence:}

François Hindré, LUNAM Université, Université d'Angers, 49933 Angers

Cedex 9, France; INSERM U1066

Micro et Nanomedecines

Biomimétiques, 49933 Angers

Cedex 9, France.

e-mail: francois.hindre@univ-angers.fr

\section{${ }^{\dagger}$ Present address:}

Claire Vanpouille-Box, Department of Pathology, New York University School of Medicine, New York, USA.
Recent experimental findings show that activation of the host immune system is required for the success of chemo- and radiotherapy. However, clinically apparent tumors have already developed multiple mechanisms to escape anti-tumor immunity. The fact that tumors are able to induce a state of tolerance and immunosuppression is a major obstacle in immunotherapy. Hence, there is an overwhelming need to develop new strategies that overcome this state of immune tolerance and induce an anti-tumor immune response both at primary and metastatic sites. Nanovectorized radiotherapy that combines ionizing radiation and nanodevices, is one strategy that could boost the quality and magnitude of an immune response in a predictable and designable fashion. The potential benefits of this emerging treatment may be based on the unique combination of immunostimulatory properties of nanoparticles with the ability of ionizing radiation to induce immunogenic tumor cell death. In this review, we will discuss available data and propose that the nanovectorized radiotherapy could be a powerful new strategy to induce anti-tumor immunity required for positive patient outcome.

\section{Keywords: anti-tumor immunity, nanoparticle, radionuclides, biomaterials, active targeting}

\section{INTRODUCTION}

The Janus face of the immune system in carcinogenesis has long been controversial and one of the most challenging in immunology. With progress in biological tools such as transgenic mouse technologies, it is now recognized that the immune system plays a dual role in cancer. For instance, it suppress tumor progression by identifying and destroying neoplastic cells (Dunn et al., 2002; Schreiber et al., 2011) but also promotes tumor growth by selecting tumor cells more adept at evading immune-mediated destruction (Khong and Restifo, 2002; Smyth et al., 2006; Zitvogel et al., 2006; Vesely et al., 2011) leading to the establishment of an immunosuppressive microenvironment that fosters carcinogenesis (Radoja et al., 2000; Whiteside, 2008). However, the host immune system not only impacts on cancer development but also on response to treatment. Experimental evidence strongly supports the concept that the activation of the immune system is essential for successful chemo- and radiotherapy (Casares et al., 2005; Apetoh et al., 2007b; Obeid et al., 2007a,b; Zitvogel et al., 2008). By improving the quality of released signals, some conventional treatments trigger a peculiar type of cell death that elicits a potent anti-tumor immune response required for positive patient outcome (Zitvogel et al., 2008). Called "immunogenic cell death" (ICD), this type of tumor cell death is defined by at least three signals: calreticulin (CRT) exposure (Obeid et al., 2007b; Zitvogel et al., 2010), release of high mobility group box-1 (HMGB-1; Apetoh et al., 2007a,b), and ATP (Ghiringhelli et al., 2009; Martins et al., 2012). Among all current available treatments, only radiotherapy (Chakraborty et al., 2004), anthracyclines (Casares et al., 2005; Mattarollo et al., 2011), oxaliplatin (Panaretakis et al., 2009; Tesniere et al., 2010), and cyclophosphamide (Schiavoni etal., 2011) have been shown to generate these signals in the proper spatiotemporal order leading to an in situ tumor vaccine (Ma et al., 2010; Hannani et al., 2011).

Therefore, conventional treatments could be used not only for their cytocidal effects but also for their ability to induce antitumor immunity. This idea extends far beyond treatments that already exhibit pro-immunogenic effects since envisioning the use of immune response modifiers (IRM) to optimize the synergy with the immune system offers great opportunities to provide alternative ways of tumor-specific immunity (Schiller et al., 2006; Cheever et al., 2008). For instance, Demaria and colleagues demonstrated significant increase in treatment efficiency when radiotherapy is combined with anti-cytotoxic T lymphocyte antigen-4 (CTLA-4; Demaria et al., 2005; Matsumura et al., 2008; Dewan et al., 2009; Pilones et al., 2009), a monoclonal antibody that blocks CTLA-4 receptor well-known to be implicated in immune tolerance (Peggs et al., 2006; O'Day et al., 2007).

In consideration of this emerging vision, the ability of anti-cancer strategies to induce anti-tumor immunity has to be investigated. Among new treatment approaches, internal radiotherapy using nanoparticles (NPs) holds great promise for the management of refractory tumors (Allard et al., 2008; Vanpouille-Box et al., 2011b). Primarily designed to focus radiation to a specific target while protecting healthy tissues from radiation, nanovectorized radiotherapy has been shown to elicit anti-tumor immunity in a preclinical model of glioblastoma (Vanpouille-Box etal., 2011a). This new treatment concept is based on the use of NPs as reservoir for radionuclides enabling 
the entrapment of alpha $(\alpha)$ and beta $(\beta)$ emitters conferring them different ways to directly kill tumor cells as well as distinct interactions with the microenvironment (Ting et al., 2010). The NP itself can also be designed to have properties of an IRM able to modify and improve the immune response through the use of peculiar biomaterials and/or surface ligands. Therefore, nanovectorized radiotherapy that combines ionizing radiation and nanodevices, is one therapy that could boost the quality and magnitude of an immune response in a predictable and designable fashion. Given the novelty of nanomedicines application, only a few studies analyzed NP's adjuvant effect on the host's innate and adaptive immune response. In this review, we will discuss available data and propose that the nanovectorized radiotherapy could be a powerful new strategy to induce anti-tumor immunity required for successful anti-cancer treatment.

\section{NANOPARTICLE: A NEW KIND OF IMMUNE RESPONSE MODIFIER}

The ideal anti-cancer treatment would be the one capable of reducing and eliminating tumors without causing any damage to surrounding healthy tissues. In that context, over the past two decades, nanotechnology-based approaches have emerged as a promising field that aims at overcoming limitations encountered in conventional anti-cancer treatments. Numerous nanodevices have been engineered using top-down or bottom-up approaches, generally ranging in dimensions from one to a few hundred nanometers in at least one dimension (Perry et al., 2011). NPs can be designed to carry therapeutics drugs (chemo- or radio-therapeutics) loaded on or within the nanocarriers by chemical conjugation or simply by encapsulation (Figure 1; Sengupta et al., 2005; Vanpouille-Box et al., 2011b; Vrignaud et al., 2011). Therefore, NPs have the ability to improve stability of encapsulated drug as compared to free entities and release in a more controlled manner over time to maintain anti-cancer agents within a therapeutic window (Amstad and Reimhult, 2012). Additionally, their flexible chemical properties allow NP surface modifications to increase their blood circulation half-life and improve their biodistribution profile. For instance, NP can be functionalized with polyethylene glycol (PEG) in order to generate a steric barrier on the surface preventing adherence

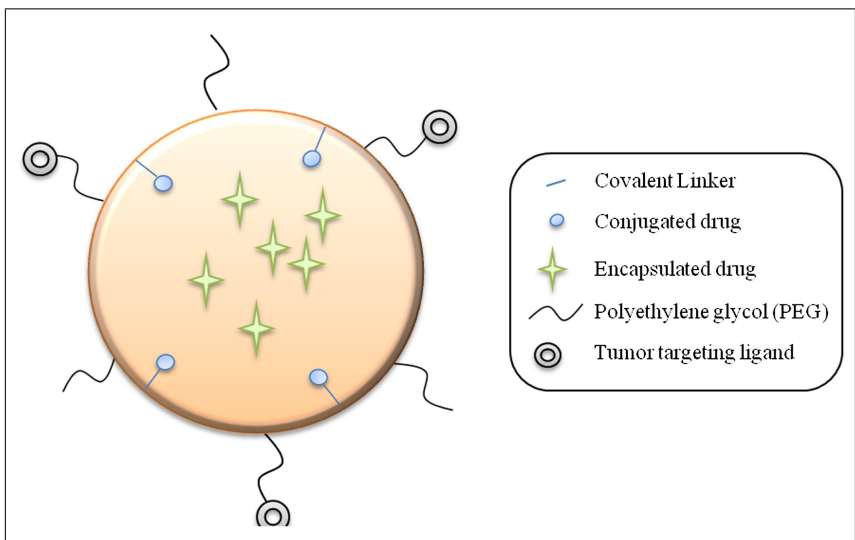

FIGURE 1 | Schematic nanoparticle. of opsonins to the NP and therefore reducing their clearance by the reticuloendothelial system (RES; Otsuka et al., 2003; Yoncheva et al., 2005).

A wide range of nanodelivery systems are currently in development. NPs can be composed of natural (Liu et al., 2011; Tavangar etal., 2011) or synthetic (Powell et al., 2011), and degradable (Huynh et al., 2009) or non-degradable polymers (Peek et al., 2008). The choice of components that constitute the nanodevice is critical as it considerably influence the NPs properties. For instance, the drug release profile can be tuned by the size and material composition of the NP (Paillard et al., 2010). Additionally, the $\mathrm{NP}$ is amenable to surface modifications (Brannon-Peppas and Blanchette, 2004; Fahmy et al., 2005; Weiss et al., 2007; Beduneau et al., 2008; Byrne et al., 2008; Hirsjarvi et al., 2011; Talekar et al., 2011) providing them targeting properties to reach specifically an organ or even a specific cell (Weissleder et al., 2005; Beduneau et al., 2008; Gu et al., 2008; Talekar et al., 2011). With this unique ability, NPs can easily be engineered to precisely synergize with the immune system and be considered as a powerful "smart" IRM designed to reach a specific location and to interact with specific cells.

As a result, we will discuss each steps that could be harnessed in NP's designing to interact with the immune system in a predictable fashion, that are (1) the choice of biomaterials that composed the NPs, (2) the proper size and charge of NPs to better synergize with the host, and (3) the possible use of ligand on NPs surface to specifically target immune or tumor cells.

\section{IMMUNE ADJUVANT PROPERTIES OF NANOPARTICLES COMPONENTS}

The main goal of immunotherapy-based strategy is to harness immune system not only to fight cancer by targeting and killing tumor cells in a specific manner, but also to alert the immune system so that the residual tumor cells are kept in check. Active forms of immunotherapy, including cancer vaccines, represent one of the promising strategies. These approaches aims at inducing the activation and expansion of tumor-specific $\mathrm{T}$ cells, which have proven to be the most powerful immune mechanism to clear tumors (Porter et al., 2011).

Many efforts have focused on enhancing cross-presentation, a process mediated by antigen presenting cells (APCs) that are defined as cells that can process antigens of both endogenous and exogenous origin (Trombetta and Mellman, 2005). Endogenous antigen (such as normal cell proteins, tumor or viral antigens) are processed in the cytosol and presented in the context of major histocompatibility complex (MHC) class I molecules to be recognized by CD8 ${ }^{+}$T cells (Figure 2; Itano and Jenkins, 2003) leading to strong cytolytic and Th1 inflammatory responses. APCs are also capable to internalize exogenous antigens. The latter are processed in specialized compartments called endocytic vesicles or endosome, and presented through MHC class II molecules to be recognized by $\mathrm{CD}^{+}{ }^{+} \mathrm{T}$ cells (Figure 3; Watts, 2004). APCs include B cells, macrophages, and dendritic cells (DC). Because of their wide distribution, location at critical sentinel sites (skin and mucosal surfaces), intrinsic migratory capacity, and ability to activate naïve T cells, DCs are considered as the most powerful professional APCs (Itano and Jenkins, 2003; Trombetta and Mellman, 2005; Delamarre and Mellman, 2011). DCs are 


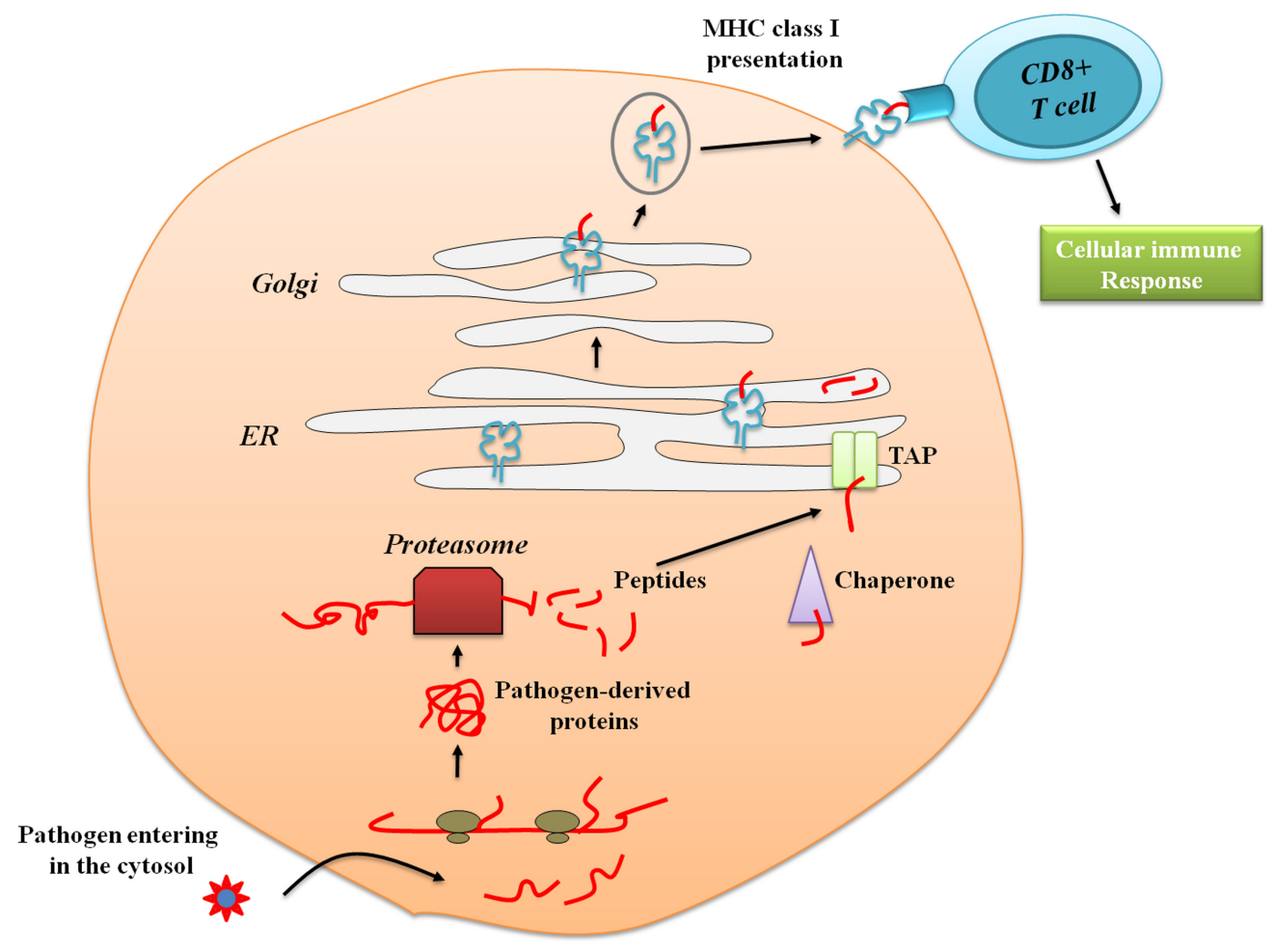

FIGURE 2 | Antigen presentation via major histocompatibility complex class I. Pathogen-derived or self-proteins within the cytosol of antigen presenting cells (APCs) are enzymatically digested into peptides, mainly by cytosolic proteases (proteasomes), and are then transported by transporter associated with antigen processing molecules (TAP) into the endoplasmic reticulum (ER). In the ER lumen, peptides bind to $\mathrm{MHC}$ class I molecules, which are subsequently transported via the Golgi to the plasma membrane. The endogenous antigen presented by $\mathrm{MHC}$ class I will then be recognized by the $\mathrm{CD}^{+}{ }^{+} \mathrm{T}$ cells leading to adaptive cellular immune responses. indeed capable of processing both exogenous and endogenous antigens and present peptide in the context of either MHC class I or II molecules. As DCs mature, they acquire the properties necessary to form and transport peptide-loaded MHC class II complexes to the cell surface (Cella et al., 1997). Antigen transport to the cell surface is correlated with increased expression of co-stimulatory molecules, such as CD80, CD86, and CD40, molecules well-known to amplify $\mathrm{T}$ cell receptor (TCR) signaling and promote T cell activation (Ni and O'Neill, 1997). Given the critical role of DC in eliciting adaptive immune response, efforts have been made to develop new strategies that target and stimulate DCs.

Nanomedicine-based treatments represent one of the main promising approaches since nanoscale drug delivery system could be thought and designed from the beginning to properly interact with the host immune system. For instance, some NPs are able to entrap drug already known to induce ICD (i.e., radionuclide; Sun and Xie, 2011; Tang et al., 2011; Vanpouille-Box et al., 2011a), oxaliplatin (Jain et al., 2010; Paraskar et al., 2012), and cyclophosphamide (Salgueiro et al., 1999), and exhibit biological effects such as endolysosomal escape (Panyam et al., 2002; Paillard et al., 2010) and biological barrier crossing (De Jong and Borm, 2008; Paillard etal., 2010). Among them, NPs of poly(D,L-lactide-co-glycolide) (PLGA) hold great promise and have been extensively studied for their ability to activate DCs for priming antigen-specific T cell responses (reviewed in Hamdy et al., 2011). PLGA is a Food and Drug Administration (FDA)approved biodegradable polymer that had been widely used in several controlled release drug products for human use (Jain, 2000; Dinarvand etal., 2011; Jain et al., 2011). One of the main characteristic of PLGA relies with its flexibility that allows manipulating its physico-chemical properties. Therefore, PLGA can shift the delivery of encapsulated drugs to either cytoplasm (for MHC class I presentation and $\mathrm{CD}^{+} \mathrm{T}$ cell activation) or to the endosome (for MHC class II and $\mathrm{CD}^{+}{ }^{+} \mathrm{T}$ cells activation; Hamdy et al., 2007, 2008; Heit et al., 2007). More recently, PLGA has been shown to activate the NOD-like receptor family pyrin domain containing 3 [NLRP3 also known as cryopyrin, cold-induced autoinflammatory syndrome 1 (CIAS1) or NALP3] inflammasome (Demento et al., 2009; Sharp et al., 2009). It has indeed been demonstrated that cellular internalization of PLGA and polystyrene microparticles activate of the NLRP3 inflammasome through lysosomal damage and caspase- 1 activation leading to the production of large amount of IL- $1 \beta$ by DCs (Sharp et al., 2009). The ability of NP's components to directly influence NLRP3 inflammasome is very important since it has been described that NLRP3 inflammasome and subsequent IL- $1 \beta$ secretion is critical for stimulation of anti-tumor $\mathrm{T}$ cells responses following chemotherapy (Ghiringhelli etal., 2009; Menu and Vince, 2011). 


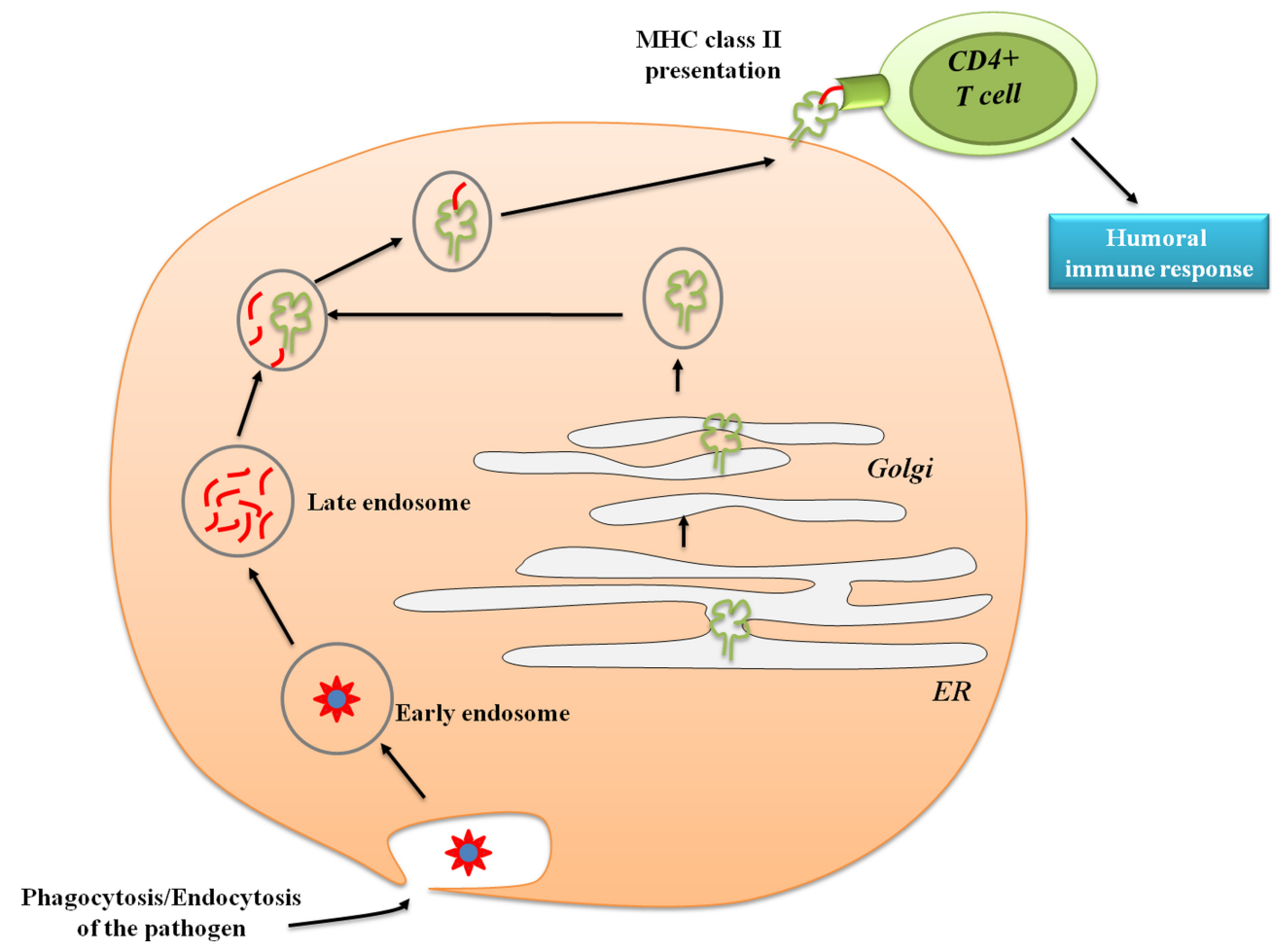

FIGURE 3 | Antigen presentation via major histocompatibility complex class II. Exogenous antigens are derived from proteins that are endocytosed and processed by proteases. Peptides bind to newly synthesized MHC class II molecules in specialized antigen-processing vesicles ( $\mathrm{MHC}$ class II-enriched compartment), and the complexes are externalized to the plasma membrane. $C D 4^{+} \mathrm{T}$ cells will then recognize the exogenous antigen presented by $\mathrm{MHC}$ class II leading to the stimulation of CD4 T cells humoral responses.
Poly(D,L-lactide-co-glycolide) is not the only strategy that has been investigated to achieve DC cross-presentation. The use of $\mathrm{pH}$-responsive materials that naturally foster antigen escape from the endosome into the cytosol where MHC class I antigen processing begins has emerged. For instance, Murthy et al. (1999) and Jones et al. (2003) have developed synthetic polymer containing alkyl(acrylic acid) monomers that become protonated at endosomal pH levels (5.5-6.5). Once protonated, the polymers destabilize the endosomal membrane and allow antigen to escape into the cytoplasm (Jones et al., 2003).

Other particle materials can stimulate signaling pathways that lead to cellular activation. Baba and colleagues have shown that poly (gamma-glutamic acid) NPs can be used as a vaccine adjuvant. These NPs induced DC maturation through MyD88-mediated nuclear factor kappa B (NF- $\mathrm{B})$ activation and the p38 mitogenactivated protein kinase (MAPK) pathways, in a manner somewhat similar to lipopolysaccharide (LPS)-induced maturation of DC (Uto et al., 2007, 2011a,b; Hamasaki et al., 2010). Therefore, NPs components act as immune adjuvant simply by inducing maturation of DC. This concept was also supported by Babensee and colleagues and Elamanchili and colleagues work, showing that exposure of bone marrow derived DC to polymers, notably PLGA, results in DC maturation as measured by the up-regulation of cell surface stimulatory markers such as MHC class II, CD40, CD80 and CD86 (Diwan et al., 2003; Elamanchili et al., 2004; Yoshida and Babensee, 2004, 2006; Yoshida et al., 2007; Babensee, 2008).
Taken together, evidences clearly indicate that nanodevices for targeted delivery of drugs or radionuclides can be composed of biomaterials that possess different immune adjuvant properties. Therefore, the choice of biomaterials to design NPs could provide a potent tool to induce anti-tumor immunity.

\section{INFLUENCE OF NANOPARTICLE SIZE AND CHARGE ON IMMUNE SYSTEM}

Another parameter to consider for immunogenic NP designing is the size and the charge of the NP. DCs and macrophages are both phagocytic cells. Hence, particles with dimension similar to pathogens $(\geq 10 \mu \mathrm{m})$ are generally readily phagocytosed. Studies have shown that DCs preferentially phagocyte smaller particles in the viral range, while macrophages more efficiently ingest bacterial size particle (Gamvrellis et al., 2004). It has also been reported that NP with a diameter $<500 \mathrm{~nm}$ were more effective in stimulating cytotoxic T lymphocytes (CTL) responses in vivo (Allsopp et al., 1996; Nixon et al., 1996). Possible explanation relies with the interactions of NPs with opsonins. Indeed, larger surface area of the NP allows more opsonins bounding and therefore, a faster degradation and rapid release of the encapsulated drug inside the phagosome (Owens and Peppas, 2006).

Additionally, physico-chemical properties of particle surface, particularly surface charge and surface chemistry, are known to affect both DC uptake and maturation. For instance, positively charged cationic particles in general have greater initial 
affinity toward cell surface than negatively charged or neutral particles (Josephson et al., 1999; Foged et al., 2005; Perez-Martinez et al., 2011).

\section{SURFACE MODIFICATION OF NANOPARTICLES}

To promote and enhance specific interactions between NP and the microenvironment, the surface of particles can be decorated with targeting moieties that are recognized specifically by targeted cells. Two main strategies can be envisioning: the one that target immune cells and the other one that target tumor cells to kills them and therefore, to provide proper "danger signal" required for immune system activation.

\section{Immune cells targeting}

In order to specifically enhance the maturation of DC, Palumbo et al. (2011) bound CD40 ligand (CD40L) on NP's surface. CD40L is indeed transiently expressed on activated $\mathrm{CD} 4^{+} \mathrm{T}$ helper cells and its binding with the CD40 receptor on DCs is important for their complete maturation and transformation into competent APC (Loskog and Totterman, 2007). However, no significant results have been reported in their studies, suggesting the complexity of conferring immunogenic properties to NPs (Palumbo et al., 2011).

In another study, Dominguez and Lustgarten (2010) engineered immunogenic NPs to induce anti-tumor immune response. They indeed succeeded in binding not only one ligand but two to further stimulate the immune system. By linking anti-neu mAb directed against a tumor antigen and anti-CD40 mAb on NP's surface, they generated an anti-tumor response resulting in tumor rejection with high production of Th1-proinflammatory cytokines, a stark reduction of regulatory $\mathrm{T}$ cells within the tumor and activation of specific cytotoxic immune response (Dominguez and Lustgarten, 2010). These recent results strongly support the potential use of biodegradable NPs to stimulate a tumor-specific immune response.

\section{Tumor cell targeting}

Specific tumor targeting could indirectly stimulate the immune system if the quantity and the quality of released signal in a specific location (i.e., the tumor) can be achieved. Many active targeting of NPs to tumor has been extensively studied and led notably to the development of NP conjugated with specific ligands that recognize a tumor-surface marker.

Over the past three decades, the generation of murine mAbs against tumor-associated antigens became a focal point of research illustrated by numerous studies being reported during the $1980 \mathrm{~s}$ that dealt with NPs and mAb binding to their surface (Leserman et al., 1980; Barbet et al., 1981; Harsch et al., 1981; Hashimoto et al., 1983; Guidoni et al., 1984). Since then, a number of clinical trials have demonstrated the feasibility of antibody-based targeting (Bernard-Marty et al., 2006; Yoong et al., 2011; Foran, 2012; Smyth and Cunningham, 2012). Among mAb that were studied, Trastuzumab (or Herceptin ${ }^{\circledR}$ ), a mAb that binds to the human epithelial growth factor receptor 2 (HER2), has been bound on NP's surface to specifically target breast cancer cells (Hayes etal., 2006; Kirpotin et al., 2006). This targeting strategy has improved therapeutic efficiency of an HER2-targeted
NPs formulation in comparison to its non-target one (Park et al., 2002).

Although antibodies have proven to be effective targeting agents, there are inherent issues such as decreased receptor affinity due to inadequate conjugation methods, insufficient tumor cell penetration, and non-specific binding of antibodies to cellular receptors. In that context, new technologies are currently being explored to enhance the selectivity and efficacy of ligands while attempting to overcome the shortcomings associated with existing targeting moiety. For example, peptides have recently emerged as targeting agent owing to the relative simplicity of synthesis and purification. The integrin family, particularly the $\alpha v \beta 3$ integrins, has been widely studied to target cancer cells with NPs. For instance, a synthetic peptide of arginine-glycine-aspartic acid (RGD) residues has been used as a ligand conjugated to NPs for targeting $\alpha v \beta 3$ integrins expressed on endothelial cells. Recent studies are further optimizing integrin targeting by engineering novel peptide moieties which bind with better affinity to integrins that current RGD tags (Ji et al., 2012; Xu et al., 2012; Zhan et al., 2012).

Binding bombesin (BBN) synthetic peptides on NP's surface is another targeting strategy in development. BBN peptides are composed with 14 amino acids and present high affinity toward gastrin-releasing peptide (GRP) receptors (Smith et al., 2005) that are overexpressed in many cancer such as prostate (Markwalder and Reubi, 1999; Nagasaki et al., 2012), breast (Chao et al., 2009), and small-cell lung carcinoma (Moody et al., 1985; Oremek and Sapoutzis, 2003). Promising results were reported, notably by Chanda et al. (2009, 2010), which demonstrated that the conjugation of BBN peptides on gold NPs' surface lead to selective uptake of NP-BBN conjugates in prostate tumor sites.

However, NPs targeting strategies are not limited to those two approaches. Conferring targeting properties to NPs was indeed one of the main focuses of nanomedicine (Katsogiannou et al., 2011; Kolhatkar et al., 2011; Talekar et al., 2011). Therefore, a plethora of ways to generate "smart" NPs targeting a specific cell is currently in development which highlights the extreme flexibility of this new technology.

\section{RADIONUCLIDES FOR NANOVECTORIZED RADIOTHERAPY}

Conventional radiotherapy (X-rays) is the mainstay adjuvant treatment of cancer. However, the radiation dose to surrounding normal tissues often limits its use and therefore, opened a very challenging research area in radiation oncology: the one that aims at reducing and destroying tumors without causing any damage to healthy tissues.

In that context, new external photon beam radiation therapy modalities have recently been emerged with the development of three-dimensional conformal radiotherapy (3D-CRT)/ volumetric-modulated arc therapy (VMAT), helical tomotherapy, intensity-modulated radiotherapy (IMRT), $\gamma$-rays $\left({ }^{60} \mathrm{Co}\right)$-knifetherapy, cyber-knife-radiotherapy-radiosurgery with 4D-imageguided tracking and 6D-image-guided stereotactic-radiotherapy, that dynamically synchronize imaging, patient positioning and treatment delivery with a dose escalation. These new approaches allow obtaining more conformal "radio-ablative" treatment of tumor lesions while minimizing the damage to the nearby normal 
tissues (Deb and Fielding, 2009; Teoh et al., 2011; Yu and Tang, 2011; Wen et al., 2012).

Another increasing successful radiation technique is the hadron therapy that uses a focus beam of quark-constituted of proton $\left(\mathrm{H}^{+}\right)$, carbon ion or neutrons, allowing more precise ionizing radiation delivery. Compared to photons (X-rays and $\gamma$-emissions), proton beams are characterized by a low entrance dose while a maximal at a user-defined depth ("Bragg peak") and almost no damage on the exit path. As a result, the chief advantage of proton therapy relies with its ability to precisely localize the radiation dosage compared to other form of external beam radiotherapy (DeLaney, 2011; Liu and Chang, 2011).

These newly developed external either photon- or especially hadron-therapy technologies are becoming more and more competitive, as for precisely target locally confined tumors, with brachytherapy modalities as alternatives options to anyhow carried out surgical approaches.

Radiation brachytherapy with either permanent interstitial implantation or temporary implant has also gained large acceptance in the last decades particularly for the management of prostate cancer (Alberti, 2011; Gomez-Veiga et al., 2012) and cervical cancer (Beddy et al., 2011; Walsh et al., 2011). This internal radiation approach is highly linked to the tumor type and size. For instance, brachytherapy is usually initiated toward the ends of external beam radiation after tumor regression has occurred and allows high doses to be delivered to the residual disease with relative sparing of surrounding normal tissues (Monk et al., 2007).

Another arm of brachytherapy consists in harnessing nanomedicines, such as radiolabeled monoclonal antibodies and/or biomaterial vectors, to generate a localized radiation (Allard et al., 2008; Barbet et al., 2012; Memon et al., 2013). As a result, with the identification of biological target overexpressed in cancer, brachytherapy is no longer limited to a specific tumor. In that context, nanovectorized radiotherapy that combines NPs and ionizing radiation is becoming a potent new radiotherapy approach that also overcomes non-specific radiation. Radioactive NPs have indeed been shown to modify the radiation distribution profile of a radionuclide by avoiding its fast elimination (Vanpouille-Box et al., 2011b) but also by maintaining radiation to a specific location for $96 \mathrm{~h}$ after their injection (VanpouilleBox et al., 2011a). Even if few data regarding radioactive particle loading capacity, specific radioactivity has been shown to be compatible with clinic application (Salem et al., 2002, 2005).

Compared to the newly developed radiotherapy strategies, nanovectorized radiotherapy presents the main advantage of being a low-cost technology by the use of radionuclides eluted from generators easily available, such as the ${ }^{188} \mathrm{~W} /{ }^{188}$ Re generator (Lepareur et al., 2011). More importantly, radioactive NPs' formulation is simple providing them high availability and accessibility to patient. As a consequence, a spread of this new technology in most of clinical institutions, including those of developing countries, can be envisioned.

Radionuclides that decay by the following three general categories of decay have been studied for therapeutic potential of nanovectorized radiotherapy: beta $(\beta)$-particles emitters (yttrium90, rhenium-188; Li et al., 2004; Tsai et al., 2011), alpha $(\alpha)$ particles emitters (bismuth 213, astatine-211; Sofou et al., 2004;
Couturier et al., 2005; Boskovitz et al., 2009) and auger electronemitters (iodine-125, gallium-67; Snelling et al., 1995). However, the extreme toxicity of auger particles as well as concerns regarding radioprotection limited their use (Bodei et al., 2003; Milenic et al., 2004). Therefore, we will focus on $\alpha$ - and $\beta$-emitters and discuss their main characteristics that may lead to different interactions with the microenvironment.

\section{ALPHA $(\alpha)$ vs. BETA ( $\beta$ ) EMITTERS}

Particles emitted during atomic decay can be classified as low or high linear energy transfer (LET) radiation. The LET corresponds to the energy released by the radiation over a certain distance (expressed in $\mathrm{keV} / \mu \mathrm{m}$ ). At absorbed doses that are equivalent to those of low-LET radiation, high-LET particles are more cytotoxic. This phenomenon is called "radiation quality." Most of the radionuclides used in internal radiotherapy; such as iodine-131 (Grunwald and Ezziddin, 2010; Leahy and Turner, 2011), yttrium90 (Kulik et al., 2008; Menda et al., 2010; Kunikowska et al., 2011), lutetium-177 (Gains et al., 2011; Kunikowska et al., 2011), ${ }^{188}$ Re (Kumar et al., 2007; Torres-Garcia et al., 2008), or rhenium-186 (Syed etal., 2006; van Dodewaard-de Jong et al., 2011); emit low-LET radiation of $0.2 \mathrm{keV} / \mu \mathrm{m}$ in the form of $\beta$-particles as well as internal conversion electrons (Milenic et al., 2004). HighLET particle emitters used in internal radiotherapy only include the $\alpha$-emitters bismuth-213, bismuth-212, and astatine-211, as well as lead-212 and actinium-225, which generate bismuth-212 and bismuth-213, respectively. These radioisotopes emit highLET radiation $(60-230 \mathrm{keV} / \mu \mathrm{m})$ that produces clusters of DNA damage that are difficult to repair.

Linear energy transfer is intimately linked to the energy carried by a particle and the depth it penetrates into the biological tissue. Therefore, $\beta$-particles carry intermediate energy $(0.50-2.30 \mathrm{MeV})$ but have a long range in tissues (1-12 $\mathrm{mm}$ of tissue penetration). This lengthy range reduces the need for cellular internalization and so targeting close to or at the cell membrane is sufficient. Additionally, the range of $\beta$-particles, as compared to the diameter of cells, allows them to traverse clusters of cells (from 10 to 1,000 cells; O'Donoghue et al., 1995).

Alpha-particles have a high energy $(5-8 \mathrm{MeV})$ and an intermediate path length $(50-80 \mu \mathrm{m})$ in biological tissues that corresponds to the diameter of several cells (2-10 cells).

Beta-emitters and alpha-emitters are produced either by cyclotron irradiation or by reactor irradiations, incorporated into a generator, and subsequently eluted (Haddad et al., 2008; Halime et al., 2009; Bakht and Sadeghi, 2011; Pillai et al., 2012). For therapeutic application, numerous criteria have to be considered while selecting a radionuclide. Therefore, regarding the tumor size, the advantage of a type of radiation decay will be preferably used in a specific application. For instance, $\beta$-particles will be more suitable radionuclides for solid tumors because of their ability to deposit a large amount of energy at a high dose rate. However, other criteria have to be considered for clinical applications: (1) availability of the radionuclide at a reasonable cost, (2) proper nuclear decay properties and absence of hindering daughter nuclides, and (3) a physical half-life long enough to allow internal radiotherapy. As a consequence, among all radionuclide available, only a few are currently developed for nanovectorized radiotherapy 


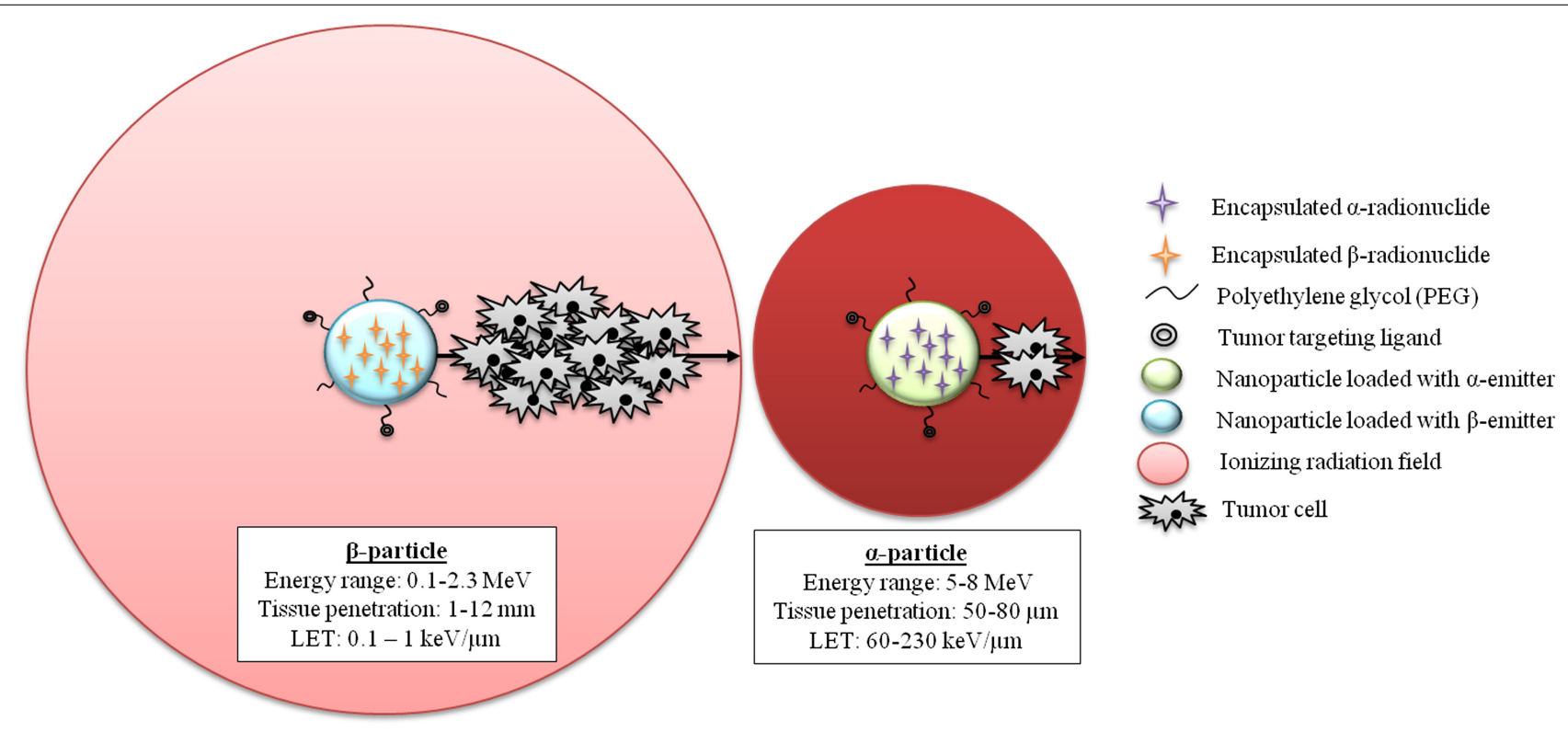

FIGURE 4 | Schematic depiction of nanoparticles loaded with beta- and alpha-emitters.

(Sofou etal., 2004; Allard etal., 2008; Hamoudeh et al., 2008; Bult et al., 2010; Vanpouille-Box et al., 2011a,b). Explanations can mainly be ascribed to the variable pertaining to their physicochemical properties and to their chemistry that could be somewhat complex according to the NP used.

It is well-established that the radiobiology of high-LET radiation differs greatly from that of low-LET radiation (Goodhead et al., 1993). For instance, increase mRNA expression of inflammatory mediators and cytokines [e.g., interferon- $\gamma($ IFN $\gamma)$ ] that prompt immune responses has been identified in lymphocytes after their exposure to low-LET radiation (Amundson et al., 2000, 2004; Kang et al., 2003). In this respect, we can suppose that APCs are able to detect radiolytic products that lead to the production of cytokines such as IFN $\gamma$, well-known to be implicated in adaptive immune response (Schoenborn and Wilson, 2007). An increased expression of genes coding for CD1C, CD1D, $\mathrm{CD} 40, \mathrm{CD} 69$, and IFN $\gamma$ in lymphocytes after $\alpha$-radiation exposure has been reported (Turtoi et al., 2010). Turtoi and Schneeweiss (2009) and Turtoi et al. (2010) indeed showed that a number of rapidly modulated early response genes in $\alpha$-particle-irradiated lymphocytes that are associated with DNA repair and immune response mechanisms. However, the current knowledge of the biology of high-LET radiation is insufficient to make definite conclusions.

\section{EFFECT OF THE NANOVECTORIZED RADIOTHERAPY ON IMMUNE SYSTEM ACTIVATION}

Immunotherapies are rarely effective as monotherapy but growing evidence supports a synergy between radiotherapy and IRM (Demaria et al., 2005; Dewan et al., 2009; Formenti and Demaria, 2009; Pilones et al., 2009; Newcomb et al., 2010). Among emerging new approaches, nanovectorized radiotherapy holds great promises as a new powerful anti-cancer treatment that could harness immunogenic properties of both NPs and ionizing radiations. Supporting this concept, we recently demonstrated that NPs loaded with rhenium-188, a $\beta$-emitter, are potent stimulators of tumor-specific immune response resulting in tumor rejection with high production of IFN $\gamma$ cytokine, increase recruitment of immune effector $\mathrm{T}$ cells within the tumor and memory response in long-term survivor animals (Vanpouille-Box et al., 2011a). Intriguingly, remarkable survival benefit was only seen when two different types of stereotactic injections were used suggesting that the distribution of NP loaded with rhenium-188 within the tumor has a direct impact on the treatment efficiency. Therefore, the use of radionuclide within NP could provide additional advantages as compared to conventional radiotherapy where the distribution of ionizing radiation is homogenous.

Much work remains to be done to determine the effects of both low-LET ( $\beta$-emitters) and high-LET ( $\alpha$-emitters) emitters on the host immune system. Nevertheless, the capability of NPs to entrap $\alpha$ - and $\beta$-radionuclides potentially provides additional means to fine tune the microenvironment interactions (Figure 4). Further investigations are required to better understand the interactions between ionizing radiations and the host immune system. Nevertheless, the potential benefits of nanovectorized radiotherapy may be based on the unique combination of immune-stimulatory NP with the ionizing radiation ability to induce an immunogenic tumor cell death.

\section{CONCLUSION}

In summary, NPs represent a potent immune adjuvant able to mimic, enhance, stimulate, and interact with the host immune system especially at the level of DCs. Although PLGA's immune effects have been studied in some details, other biomaterials used to produce NP may have different chemical properties that affect immune cells. Given the considerable variety of biomaterials that 
can be used to design NPs, further investigations that aim at identifying the immune stimulant abilities of NP's components are required. This could be very critical to develop personalized nanomedicine that aims to induce anti-tumor immunity in a predictable and desirable fashion. Similar to the immune system itself, nanodevices present tremendous flexibility and plasticity and could be therefore considered as an IRM platform capable to be tailored according to the desired application. Their unique abilities to encapsulate a high payload of radionuclide; notably

\section{REFERENCES}

Alberti, C. (2011). Organ-confined prostate carcinoma radiation brachytherapy compared with external either photon- or hadron-beam radiation therapy. Just a short up-todate. Eur. Rev. Med. Pharmacol. Sci. $15,769-774$.

Allard, E., Hindre, F., Passirani, C., Lemaire, L., Lepareur, N., Noiret, N., et al. (2008). 188Re-loaded lipid nanocapsules as a promising radiopharmaceutical carrier for internal radiotherapy of malignant gliomas. Eur. J. Nucl. Med. Mol. Imaging 35, 1838-1846.

Allsopp, C. E., Plebanski, M., Gilbert, S., Sinden, R. E., Harris, S., Frankel, G., et al. (1996). Comparison of numerous delivery systems for the induction of cytotoxic $\mathrm{T}$ lymphocytes by immunization. Eur. J. Immunol. 26, 1951-1959.

Amstad, E., and Reimhult, E. (2012). Nanoparticle actuated hollow drug delivery vehicles. Nanomedicine (Lond.) 7, 145-164.

Amundson, S. A., Do, K. T., Shahab, S., Bittner, M., Meltzer, P., Trent, J., et al. (2000). Identification of potential mRNA biomarkers in peripheral blood lymphocytes for human exposure to ionizing radiation. Radiat. Res. 154, 342-346.

Amundson, S. A., Grace, M. B., Mcleland, C. B., Epperly, M. W., Yeager, A., Zhan, Q., et al. (2004). Human in vivo radiation-induced biomarkers: gene expression changes in radiotherapy patients. Cancer Res. 64, 6368-6371.

Apetoh, L., Ghiringhelli, F., Tesniere, A., Criollo, A., Ortiz, C., Lidereau, R., etal. (2007a). The interaction between HMGB1 and TLR4 dictates the outcome of anticancer chemotherapy and radiotherapy. Immunol. Rev. 220, 47-59.

Apetoh, L., Ghiringhelli, F., Tesniere, A., Obeid, M., Ortiz, C., Criollo, A., et al. (2007b). Toll-like receptor 4-dependent contribution of the immune system to anticancer chemotherapy and radiotherapy. Nat. Med. 13, 1050-1059.
Babensee, J. E. (2008). Interaction of dendritic cells with biomaterials. Semin. Immunol. 20, 101-108.

Bakht, M. K., and Sadeghi, M. (2011). Internal radiotherapy techniques using radiolanthanide praseodymium-142: a review of production routes, brachytherapy, unsealed source therapy. Ann. Nucl. Med. 25, 529-535.

Barbet, J., Bardies, M., Bourgeois, M., Chatal, J. F., Cherel, M., Davodeau, F. et al. (2012). Radiolabeled antibodies for cancer imaging and therapy. Methods Mol. Biol. 907, 681-697.

Barbet, J., Machy, P., and Leserman, L. D. (1981). Monoclonal antibody covalently coupled to liposomes: specific targeting to cells. J. Supramol. Struct. Cell. Biochem. 16, 243-258.

Beddy, P., Rangarajan, R. D., and Sala, E. (2011). Role of MRI in intracavitary brachytherapy for cervical cancer: what the radiologist needs to know. AJR Am. J. Roentgenol. 196 W341-W347.

Beduneau, A., Hindre, F., Clavreul, A., Leroux, J. C., Saulnier, P., and Benoit, J. P. (2008). Brain targeting using novel lipid nanovectors. J. Control. Release 126, 44-49.

Bernard-Marty, C., Lebrun, F., Awada, A., and Piccart, M. J. (2006). Monoclonal antibody-based targeted therapy in breast cancer: current status and future directions. Drugs 66, 1577-1591.

Bodei, L., Kassis, A. I., Adelstein, S. J., and Mariani, G (2003). Radionuclide therapy with iodine-125 and other auger-electronemitting radionuclides: experimental models and clinical applications. Cancer Biother. Radiopharm. 18, 861877.

Boskovitz, A., Mclendon, R. E., Okamura, T., Sampson, J. H., Bigner, D. D., and Zalutsky, M. R. (2009). Treatment of HER2-positive breast carcinomatous meningitis with intrathecal administration of alphaparticle-emitting (211)At-labeled trastuzumab. Nucl. Med. Biol. 36, 659-669.

Brannon-Peppas, L., and Blanchette, J. O. (2004). Nanoparticle and targeted

high-LET $\alpha$-particles and low-LET $\beta$-emitters; and to undergo surface modifications, further support their strong potential as a new anti-cancer strategy enable to induce effective anti-tumor immunity.

Much remains to be learned about the effect of nanovectorized radiotherapy but initial data showing that the delivery of ionizing radiation via NPs can be effective at inducing antitumor immunity suggest that this new approach warrants further investigations.

systems for cancer therapy. Adv. Drug Deliv. Rev. 56, 1649-1659.

Bult, W., Varkevisser, R., Soulimani, F., Seevinck, P. R., De Leeuw, H., Bakker, C. J., et al. (2010). Holmium nanoparticles: preparation and in vitro characterization of a new device for radioablation of solid malignancies. Pharm. Res. 27, 2205-2212.

Byrne, J. D., Betancourt, T., and Brannon-Peppas, L. (2008). Active targeting schemes for nanoparticle systems in cancer therapeutics. $A d v$ Drug Deliv. Rev. 60, 1615-1626.

Casares, N., Pequignot, M. O., Tesniere, A., Ghiringhelli, F., Roux, S., Chaput, N., etal. (2005). Caspase-dependent immunogenicity of doxorubicin-induced tumor cell death. J. Exp. Med. 202, 1691-1701.

Cella, M., Sallusto, F., and Lanzavecchia, A. (1997). Origin, maturation and antigen presenting function of dendritic cells. Curr. Opin. Immunol. 9, 10-16.

Chakraborty, M., Abrams, S. I., Coleman, C. N., Camphausen, K., Schlom, J., and Hodge, J. W. (2004). External beam radiation of tumors alters phenotype of tumor cells to render them susceptible to vaccine-mediated T-cell killing. Cancer Res. 64, 43284337.

Chanda, N., Kattumuri, V., Shukla, R., Zambre, A., Katti, K., Upendran, A., et al. (2010). Bombesin functionalized gold nanoparticles show in vitro and in vivo cancer receptor specificity. Proc. Natl. Acad. Sci. U.S.A. 107, 8760-8765.

Chanda, N., Shukla, R., Katti, K. V., and Kannan, R. (2009). Gastrin releasing protein receptor specific gold nanorods: breast and prostate tumor avid nanovectors for molecular imaging. Nano Lett. 9, 1798-1805.

Chao, C., Ives, K., Hellmich, $\mathrm{H}$ L., Townsend, C. M. Jr., and Hellmich, M. R. (2009). Gastrinreleasing peptide receptor in breast cancer mediates cellular migration and interleukin-8 expression. J. Surg. Res. 156, 26-31.

Cheever, M. A., Schlom, J., Weiner, L. M., Lyerly, H. K., Disis, M. L., Greenwood, A., et al.
(2008). Translational Research Working Group developmental pathway for immune response modifiers. Clin. Cancer Res. 14, 5692-5699.

Couturier, O., Supiot, S., DegraefMougin, M., Faivre-Chauvet, A., Carlier, T., Chatal, J. F., et al. (2005). Cancer radioimmunotherapy with alpha-emitting nuclides. Eur. J. Nucl. Med. Mol. Imaging 32, 601-614.

Deb, P., and Fielding, A. (2009). Radiobiological model comparison of $3 \mathrm{D}$ conformal radiotherapy and IMRT plans for the treatment of prostate cancer. Australas. Phys. Eng. Sci. Med. 32, 51-61.

De Jong, W. H., and Borm, P. J. (2008). Drug delivery and nanoparticles: applications and hazards. Int. J. Nanomed. 3, 133-149.

Delamarre, L., and Mellman, I. (2011). Harnessing dendritic cells for immunotherapy. Semin. Immunol. 23, 2-11.

DeLaney, T. F. (2011). Proton therapy in the clinic. Front. Radiat. Ther. Oncol. 43, 465-485.

Demaria, S., Kawashima, N., Yang, A. M., Devitt, M. L., Babb, J. S., Allison, J. P., et al. (2005). Immune-mediated inhibition of metastases after treatment with local radiation and CTLA4 blockade in a mouse model of breast cancer. Clin. Cancer Res. 11, 728-734. Demento, S. L., Eisenbarth, S. C., Foellmer, H. G., Platt, C., Caplan, M. J., Mark Saltzman, W., et al. (2009). Inflammasome-activating nanoparticles as modular systems for optimizing vaccine efficacy. Vaccine 27 , 3013-3021.

Dewan, M. Z., Galloway, A. E., Kawashima, N., Dewyngaert, J. K., Babb, J. S., Formenti, S. C., etal. (2009). Fractionated but not single-dose radiotherapy induces an immune-mediated abscopal effect when combined with anti-CTLA-4 antibody. Clin. Cancer Res. 15, 53795388.

Dinarvand, R., Sepehri, N., Manoochehri, S., Rouhani, H., and Atyabi, F. (2011). Polylactide-coglycolide nanoparticles for controlled delivery of anticancer agents. Int. J. Nanomed. 6, 877-895. 
Diwan, M., Elamanchili, P., Lane, H., Gainer, A., and Samuel, J. (2003). Biodegradable nanoparticle mediated antigen delivery to human cord blood derived dendritic cells for induction of primary $\mathrm{T}$ cell responses. J. Drug Target. 11, 495-507.

Dominguez, A. L., and Lustgarten, J. (2010). Targeting the tumor microenvironment with anti-neu/anti-CD40 conjugated nanoparticles for the induction of antitumor immune responses. Vaccine 28, 1383-1390.

Dunn, G. P., Bruce, A. T., Ikeda, H., Old, L. J., and Schreiber, R. D. (2002). Cancer immunoediting: from immunosurveillance to tumor escape. Nat. Immunol. 3, 991-998.

Elamanchili, P., Diwan, M., Cao, M. and Samuel, J. (2004). Characterization of poly(D,L-lactic-co-glycolic acid) based nanoparticulate system for enhanced delivery of antigens to dendritic cells. Vaccine 22, 24062412.

Fahmy, T. M., Samstein, R. M., Harness, C. C., and Mark Saltzman, W. (2005) Surface modification of biodegradable polyesters with fatty acid conjugates for improved drug targeting. Biomaterials 26, 5727-5736.

Foged, C., Brodin, B., Frokjaer, S., and Sundblad, A. (2005). Particle size and surface charge affect particle uptake by human dendritic cells in an in vitro model. Int. J. Pharm. 298, 315-322.

Foran, J. M. (2012). Targeted therapy of acute myeloid leukemia in 2012: towards individualized therapy. Hematology 17(Suppl. 1), 137-140.

Formenti, S. C., and Demaria, S. (2009). Systemic effects of local radiotherapy. Lancet Oncol. 10, 718-726.

Gains, J. E., Bomanji, J. B., Fersht, N. L., Sullivan, T., D’Souza, D., Sullivan, K. P., etal. (2011). 177LuDOTATATE molecular radiotherapy for childhood neuroblastoma. J. Nucl. Med. 52, 1041-1047.

Gamvrellis, A., Leong, D., Hanley, J. C., Xiang, S. D., Mottram, P., and Plebanski, M. (2004). Vaccines that facilitate antigen entry into dendritic cells. Immunol. Cell Biol. 82, 506-516.

Ghiringhelli, F., Apetoh, L., Tesniere, A., Aymeric, L., Ma, Y., Ortiz, C., et al. (2009). Activation of the NLRP3 inflammasome in dendritic cells induces IL-1beta-dependent adaptive immunity against tumors. Nat. Med. 15, 1170-1178.

Gomez-Veiga, F., Marino, A., Alvarez, L., Rodriguez, I., Fernandez, C., Pertega, S., et al. (2012). Brachytherapy for the treatment of recurrent prostate cancer after radiotherapy or radical prostatectomy. BJU Int. 109(Suppl. 1), 17-21.

Goodhead, D. T., Thacker, J., and Cox, R. (1993). Weiss Lecture. Effects of radiations of different qualities on cells: molecular mechanisms of damage and repair. Int. J. Radiat. Biol. 63, 543-556.

Grunwald, F., and Ezziddin, S. (2010). 131I-metaiodobenzylguanidine therapy of neuroblastoma and other neuroendocrine tumors. Semin. Nucl. Med. 40, 153-163.

Gu, F., Zhang, L., Teply, B. A., Mann, N., Wang, A., Radovic-Moreno, A. F., et al. (2008). Precise engineering of targeted nanoparticles by using self-assembled biointegrated block copolymers. Proc. Natl. Acad. Sci. U.S.A. 105, 2586-2591.

Guidoni, L., O’Hara, C. J., Price, G. B., Shuster, J., and Fuks, A. (1984). Targeting of liposomes: monoclonal antibodies coupled to phospholipid vesicles provide selective transfer of trapped reagents into cultured cells. Tumour Biol. 5, 61-73.

Haddad, F., Ferrer, L., Guertin, A. Carlier, T., Michel, N., Barbet, J., et al. (2008). ARRONAX, a highenergy and high-intensity cyclotron for nuclear medicine. Eur. J. Nucl. Med. Mol. Imaging 35, 1377-1387.

Halime, Z., Lachkar, M., and Boitrel, B. (2009). Coordination of bismuth and lead in porphyrins: towards an in-situ generator for alpha-radiotherapy? Biochimie 91, 1318-1320.

Hamasaki, T., Uto, T., Akagi, T., Akashi, M., and Baba, M. (2010). Modulation of gene expression related to Toll-like receptor signaling in dendritic cells by poly(gamma-glutamic acid) nanoparticles. Clin. Vaccine Immunol. 17, 748-756.

Hamdy, S., Elamanchili, P., Alshamsan, A., Molavi, O., Satou, T., and Samuel, J. (2007). Enhanced antigen-specific primary CD4+ and CD8+ responses by codelivery of ovalbumin and tolllike receptor ligand monophosphoryl lipid A in poly(D,L-lactic-co-glycolic acid) nanoparticles. J. Biomed. Mater. Res. A 81, 652-662.

Hamdy, S., Haddadi, A., Hung, R. W., and Lavasanifar, A. (2011). Targeting dendritic cells with nanoparticulate PLGA cancer vaccine formulations. Adv. Drug Deliv. Rev. 63, 943-955.

Hamdy, S., Molavi, O., Ma, Z., Haddadi, A., Alshamsan, A., Gobti, Z., et al. (2008). Co-delivery of cancer-associated antigen and Tolllike receptor 4 ligand in PLGA nanoparticles induces potent CD8+ $\mathrm{T}$ cell-mediated anti-tumor immunity. Vaccine 26, 5046-5057.
Hamoudeh, M., Fessi, H., Salim, H., and Barbos, D. (2008). Holmiumloaded PLLA nanoparticles for intratumoral radiotherapy via the TMT technique: preparation, characterization, and stability evaluation after neutron irradiation. Drug Dev. Ind. Pharm. 34, 796-806.

Hannani, D., Sistigu, A., Kepp, O., Galluzzi, L., Kroemer, G., and Zitvogel, L. (2011). Prerequisites for the antitumor vaccine-like effect of chemotherapy and radiotherapy. Cancer J. 17, 351-358.

Harsch, M., Walther, P., and Weder, H. G. (1981). Targeting of monoclonal antibody-coated liposomes to sheep red blood cells. Biochem. Biophys. Res. Commun. 103, 1069-1076.

Hashimoto, Y., Sugawara, M., and Endoh, H. (1983). Coating of liposomes with subunits of monoclonal IgM antibody and targeting of the liposomes. J. Immunol. Methods 62, 155-162.

Hayes, M. E., Drummond, D. C., Hong, K., Zheng, W. W., Khorosheva, V. A., Cohen, J. A., et al. (2006). Increased target specificity of anti-HER2 genospheres by modification of surface charge and degree of PEGylation. Mol. Pharm. 3, 726-736.

Heit, A., Schmitz, F., Haas, T., Busch, D. H., and Wagner, H. (2007). Antigen co-encapsulated with adjuvants efficiently drive protective T cell immunity. Eur. J. Immunol. 37, 2063-2074.

Hirsjarvi, S., Passirani, C., and Benoit, J. P. (2011). Passive and active tumour targeting with nanocarriers. Curr. Drug Discov. Technol. 8, 188-196.

Huynh, N. T., Passirani, C., Saulnier, P., and Benoit, J. P. (2009). Lipid nanocapsules: a new platform for nanomedicine. Int. J. Pharm. 379, 201-209.

Itano, A. A., and Jenkins, M. K. (2003). Antigen presentation to naive CD4 $\mathrm{T}$ cells in the lymph node. Nat. Immunol. 4, 733-739.

Jain, A., Jain, S. K., Ganesh, N. Barve, J., and Beg, A. M. (2010). Design and development of ligandappended polysaccharidic nanoparticles for the delivery of oxaliplatin in colorectal cancer. Nanomedicine 6, 179-190.

Jain, A. K., Das, M., Swarnakar, N. K., and Jain, S. (2011). Engineered PLGA nanoparticles: an emerging delivery tool in cancer therapeutics. Crit. Rev. Ther. Drug Carrier Syst. 28, $1-45$.

Jain, R. A. (2000). The manufacturing techniques of various drug loaded biodegradable poly(lactideco-glycolide) (PLGA) devices. Biomaterials 21, 2475-2490.
Ji, S., Xu, J., Zhang, B., Yao, W., Xu, W., Wu, W., etal. (2012). RGDconjugated albumin nanoparticles as a novel delivery vehicle in pancreatic cancer therapy. Cancer Biol. Ther. 13, 206-215.

Jones, R. A., Cheung, C. Y., Black, F. E., Zia, J. K., Stayton, P. S., Hoffman, A. S., et al. (2003). Poly(2-alkylacrylic acid) polymers deliver molecules to the cytosol by $\mathrm{pH}$-sensitive disruption of endosomal vesicles. Biochem. J. 372, 65-75.

Josephson, L., Tung, C. H., Moore, A., and Weissleder, R. (1999). High-efficiency intracellular magnetic labeling with novel superparamagnetic-Tat peptide conjugates. Bioconjug. Chem. 10, 186-191.

Kang, C. M., Park, K. P., Song, J. E., Jeoung, D. I., Cho, C. K., Kim, T. H., et al. (2003). Possible biomarkers for ionizing radiation exposure in human peripheral blood lymphocytes. Radiat. Res. 159, 312-319.

Katsogiannou, M., Peng, L., Catapano, C. V., and Rocchi, P. (2011). Activetargeted nanotherapy strategies for prostate cancer. Curr. Cancer Drug. Targets 11, 954-965.

Khong, H. T., and Restifo, N. P. (2002). Natural selection of tumor variants in the generation of "tumor escape" phenotypes. Nat. Immunol. 3, 9991005.

Kirpotin, D. B., Drummond, D. C., Shao, Y., Shalaby, M. R., Hong, K., Nielsen, U. B., et al. (2006). Antibody targeting of longcirculating lipidic nanoparticles does not increase tumor localization but does increase internalization in animal models. Cancer Res. 66, 67326740 .

Kolhatkar, R., Lote, A., and Khambati, H. (2011). Active tumor targeting of nanomaterials using folic acid, transferrin and integrin receptors. Curr. Drug Discov. Technol. 8, 197-206.

Kulik, L. M., Carr, B. I., Mulcahy, M. F., Lewandowski, R. J., Atassi, B., Ryu, R. K., et al. (2008). Safety and efficacy of $90 \mathrm{Y}$ radiotherapy for hepatocellular carcinoma with and without portal vein thrombosis. Hepatology 47, 71-81.

Kumar, A., Srivastava, D. N., Chau, T. T., Long, H. D., Bal, C., Chandra, P., et al. (2007). Inoperable hepatocellular carcinoma: transarterial 188Re HDD-labeled iodized oil for treatment - prospective multicenter clinical trial. Radiology 243, 509-519.

Kunikowska, J., Krolicki, L., Hubalewska-Dydejczyk, A., Mikolajczak, R., Sowa-Staszczak, A., and Pawlak, D. (2011). Clinical results of radionuclide therapy 
of neuroendocrine tumours with 90Y-DOTATATE and tandem 90Y/177Lu-DOTATATE: which is a better therapy option? Eur. J. Nucl. Med. Mol. Imaging 38, 1788-1797.

Leahy, M. F., and Turner, J. H. (2011). Radioimmunotherapy of relapsed indolent non-Hodgkin lymphoma with 131I-rituximab in routine clinical practice: 10-year single-institution experience of 142 consecutive patients. Blood 117, 45-52.

Lepareur, N., Ardisson, V., Noiret, N., Boucher, E., Raoul, J. L., Clement, B., et al. (2011). Automation of labelling of Lipiodol with highactivity generator-produced 188Re. Appl. Radiat. Isot. 69, 426-430.

Leserman, L. D., Barbet, J., Kourilsky, F., and Weinstein, J. N. (1980). Targeting to cells of fluorescent liposomes covalently coupled with monoclonal antibody or protein A. Nature 288, 602-604.

Li, L., Wartchow, C. A., Danthi, S. N., Shen, Z., Dechene, N., Pease, J., et al. (2004). A novel antiangiogenesis therapy using an integrin antagonist or anti-Flk-1 antibody coated 90Y-labeled nanoparticles. Int. J. Radiat. Oncol. Biol. Phys. 58, 12151227.

Liu, H., and Chang, J. Y. (2011). Proton therapy in clinical practice. Chin. J. Cancer 30, 315-326.

Liu, Y., Lou, C., Yang, H., Shi, M., and Miyoshi, H. (2011). Silica nanoparticles as promising drug/gene delivery carriers and fluorescent nano-probes: recent advances. Curr. Cancer Drug. Targets 11, 156-163.

Loskog, A., and Totterman, T. H. (2007). CD40L - a multipotent molecule for tumor therapy. Endocr. Metab. Immune Disord. Drug Targets 7, 23-28.

Ma, Y., Kepp, O., Ghiringhelli, F., Apetoh, L., Aymeric, L., Locher, C., et al. (2010). Chemotherapy and radiotherapy: cryptic anticancer vaccines. Semin. Immunol. 22, 113-124.

Markwalder, R., and Reubi, J. C. (1999). Gastrin-releasing peptide receptors in the human prostate: relation to neoplastic transformation. Cancer Res. 59, 1152-1159.

Martins, I., Michaud, M., Sukkurwala, A. Q., Adjemian, S., Ma, Y., Shen, S., etal. (2012). Premortem autophagy determines the immunogenicity of chemotherapyinduced cancer cell death. Autophagy 8, 413-415.

Matsumura, S., Wang, B., Kawashima, N., Braunstein, S., Badura, M., Cameron, T. O., et al. (2008). Radiation-induced CXCL16 release by breast cancer cells attracts effector T cells. J. Immunol. 181, 3099-3107.

Mattarollo, S. R., Loi, S., Duret, H., Ma, Y., Zitvogel, L., and Smyth, M. J. (2011). Pivotal role of innate and adaptive immunity in anthracycline chemotherapy of established tumors. Cancer Res. 71, 4809-4820.

Memon, K., Lewandowski, R. J., Riaz, A., and Salem, R. (2013). Yttrium 90 microspheres for the treatment of hepatocellular carcinoma. Recent Results Cancer Res. 190, 207-224.

Menda, Y., O’Dorisio, M. S., Kao, S., Khanna, G., Michael, S., Connolly, M., et al. (2010). Phase I trial of 90Y-DOTATOC therapy in children and young adults with refractory solid tumors that express somatostatin receptors. J. Nucl. Med. 51, 1524-1531.

Menu, P., and Vince, J. E. (2011). The NLRP3 inflammasome in health and disease: the good, the bad and the ugly. Clin. Exp. Immunol. 166, 1-15.

Milenic, D. E., Brady, E. D., and Brechbiel, M. W. (2004). Antibody-targeted radiation cancer therapy. Nat. Rev. Drug Discov. 3, 488-499.

Monk, B. J., Tewari, K. S., and Koh, W. J. (2007). Multimodality therapy for locally advanced cervical carcinoma: state of the art and future directions. J. Clin. Oncol. 25, 2952-2965.

Moody, T. W., Carney, D. N., Cuttitta, F., Quattrocchi, K., and Minna, J. D. (1985). High affinity receptors for bombesin/GRP-like peptides on human small cell lung cancer. Life Sci. 37, 105-113.

Murthy, N., Robichaud, J. R., Tirrell, D. A., Stayton, P. S., and Hoffman, A. S. (1999). The design and synthesis of polymers for eukaryotic membrane disruption. J. Control. Release 61, 137-143.

Nagasaki, S., Nakamura, Y., Maekawa, T., Akahira, J., Miki, Y., Suzuki, T., et al. (2012). Immunohistochemical analysis of gastrin-releasing peptide receptor (GRPR) and possible regulation by estrogen receptor betacx in human prostate carcinoma. $\mathrm{NeO}$ plasma 59, 224-232.

Newcomb, E. W., Lukyanov, Y., Kawashima, N., Alonso-Basanta, M., Wang, S. C., Liu, M., et al. (2010). Radiotherapy enhances antitumor effect of anti-CD137 therapy in a mouse Glioma model. Radiat. Res. 173, 426-432.

Ni, K., and O’Neill, H. C. (1997). The role of dendritic cells in $\mathrm{T}$ cell activation. Immunol. Cell Biol. 75, 223-230.

Nixon, D. F., Hioe, C., Chen, P. D., Bian, Z., Kuebler, P., Li, M. L., et al. (1996). Synthetic peptides entrapped in microparticles can elicit cytotoxic T cell activity. Vaccine 14 1523-1530.

Obeid, M., Panaretakis, T., Joza, N., Tufi, R., Tesniere, A., Van Endert, P., et al. (2007a). Calreticulin exposure is required for the immunogenicity of gamma-irradiation and UVC lightinduced apoptosis. Cell Death. Differ. 14, 1848-1850.

Obeid, M., Tesniere, A., Ghiringhelli, F., Fimia, G. M., Apetoh, L., Perfettini, J. L., et al. (2007b). Calreticulin exposure dictates the immunogenicity of cancer cell death. Nat. Med. 13, 54-61.

O'Day, S. J., Hamid, O., and Urba, W. J. (2007). Targeting cytotoxic Tlymphocyte antigen-4 (CTLA-4): a novel strategy for the treatment of melanoma and other malignancies. Cancer 110, 2614-2627.

O'Donoghue, J. A., Bardies, M., and Wheldon, T. E. (1995). Relationships between tumor size and curability for uniformly targeted therapy with betaemitting radionuclides. J. Nucl. $\mathrm{Med}$. 36, 1902-1909.

Oremek, G. M., and Sapoutzis, N. (2003). Pro-gastrin-releasing peptide (Pro-GRP), a tumor marker for small cell lung cancer. Anticancer. Res. 23, 895-898.

Otsuka, H., Nagasaki, Y., and Kataoka, K. (2003). PEGylated nanoparticles for biological and pharmaceutical applications. Adv. Drug Deliv. Rev. 55, 403-419.

Owens, D. E. III, and Peppas, N. A. (2006). Opsonization, biodistribution, and pharmacokinetics of polymeric nanoparticles. Int. J. Pharm. 307, 93-102.

Paillard, A., Hindre, F., VignesColombeix, C., Benoit, J. P., and Garcion, E. (2010). The importance of endo-lysosomal escape with lipid nanocapsules for drug subcellular bioavailability. Biomaterials 31, 7542-7554.

Palumbo, R. N., Nagarajan, L., and Wang, C. (2011). Recombinant monomeric CD40 ligand for delivering polymer particles to dendritic cells. Biotechnol. Prog. 27, 830-837.

Panaretakis, T., Kepp, O., Brockmeier, U., Tesniere, A., Bjorklund, A. C., Chapman, D. C., et al. (2009). Mechanisms of pre-apoptotic calreticulin exposure in immunogenic cell death. EMBO J. 28, 578-590.

Panyam, J., Zhou, W. Z., Prabha, S., Sahoo, S. K., and Labhasetwar, V. (2002). Rapid endo-lysosomal escape of poly(DL-lactide-co-glycolide) nanoparticles: implications for drug and gene delivery. FASEB J. 16, 1217-1226.
Paraskar, A., Soni, S., Roy, B., Papa, A. L., and Sengupta, S. (2012). Rationally designed oxaliplatin-nanoparticle for enhanced antitumor efficacy. Nanotechnology 23, 075103.

Park, J. W., Hong, K., Kirpotin, D. B., Colbern, G., Shalaby, R., Baselga, J., et al. (2002). Anti-HER2 immunoliposomes: enhanced efficacy attributable to targeted delivery. Clin. Cancer Res. 8, 1172-1181.

Peek, L. J., Middaugh, C. R., and Berkland, C. (2008). Nanotechnology in vaccine delivery. Adv. Drug Deliv. Rev. 60, 915-928.

Peggs, K. S., Quezada, S. A., Korman, A. J., and Allison, J. P. (2006). Principles and use of anti-CTLA4 antibody in human cancer immunotherapy. Curr. Opin. Immunol. 18, 206-213.

Perez-Martinez, F. C., Guerra, J., Posadas, I., and Cena, V. (2011). Barriers to non-viral vector-mediated gene delivery in the nervous system. Pharm. Res. 28, 1843-1858.

Perry, J. L., Herlihy, K. P., Napier, M. E., and Desimone, J. M. (2011). PRINT: a novel platform toward shape and size specific nanoparticle theranostics. Acc. Chem. Res. 44, 990-998.

Pillai, M. R., Dash, A., and Knapp, F. F. (2012). Rhenium-188: availability from the $188 \mathrm{~W} / 188 \mathrm{Re}$ generator and status of current applications. Curr. Radiopharm. 5, 228-243.

Pilones, K. A., Kawashima, N., Yang, A. M., Babb, J. S., Formenti, S. C., and Demaria, S. (2009). Invariant natural killer $\mathrm{T}$ cells regulate breast cancer response to radiation and CTLA4 blockade. Clin. Cancer Res. 15, 597-606.

Porter, D. L., Levine, B. L., Kalos, M., Bagg, A., and June, C. H. (2011). Chimeric antigen receptor-modified T cells in chronic lymphoid leukemia. N. Engl. J. Med. 365, 725-733.

Powell, T. J., Palath, N., Derome, M. E., Tang, J., Jacobs, A., and Boyd, J. G. (2011). Synthetic nanoparticle vaccines produced by layer-by-layer assembly of artificial biofilms induce potent protective T-cell and antibody responses in vivo. Vaccine 29, 558-569.

Radoja, S., Rao, T. D., Hillman, D., and Frey, A. B. (2000). Mice bearing latestage tumors have normal functional systemic $\mathrm{T}$ cell responses in vitro and in vivo. J. Immunol. 164, 2619-2628.

Salem, R., Lewandowski, R. J., Atassi, B., Gordon, S. C., Gates, V. L., Barakat, O., etal. (2005). Treatment of unresectable hepatocellular carcinoma with use of $90 \mathrm{Y}$ microspheres (TheraSphere): safety, tumor response, and survival. J. Vasc. Interv. Radiol. 16, 1627-1639. 
Salem, R., Thurston, K. G., Carr, B. I., Goin, J. E., and Geschwind, J. F. (2002). Yttrium-90 microspheres: radiation therapy for unresectable liver cancer. J. Vasc. Interv. Radiol. 13 , S223-S229.

Salgueiro, A., Egea, M. A., Valls, R., Espina, M., and Garcia, M. L. (1999). An inductively coupled plasma method for determination of cyclophosphamide loaded to polymeric systems. J. Pharm. Biomed. Anal. 21, 611-618.

Schiavoni, G., Sistigu, A., Valentini, M., Mattei, F., Sestili, P., Spadaro, F., et al. (2011). Cyclophosphamide synergizes with type I interferons through systemic dendritic cell reactivation and induction of immunogenic tumor apoptosis. Cancer Res. 71, 768-778.

Schiller, M., Metze, D., Luger, T. A., Grabbe, S., and Gunzer, M. (2006). Immune response modifiersmode of action. Exp. Dermatol. 15, 331-341.

Schoenborn, J. R., and Wilson, C. B. (2007). Regulation of interferongamma during innate and adaptive immune responses. Adv. Immunol. 96, 41-101.

Schreiber, R. D., Old, L. J., and Smyth, M. J. (2011). Cancer immunoediting: integrating immunity's roles in cancer suppression and promotion. Science 331, 1565-1570.

Sengupta, S., Eavarone, D., Capila, I., Zhao, G., Watson, N., Kiziltepe, T., et al. (2005). Temporal targeting of tumour cells and neovasculature with a nanoscale delivery system. Nature 436, 568-572.

Sharp, F. A., Ruane, D., Claass, B., Creagh, E., Harris, J., Malyala, P., etal. (2009). Uptake of particulate vaccine adjuvants by dendritic cells activates the NALP3 inflammasome. Proc. Natl. Acad. Sci. U.S.A. 106, 870-875.

Smith, C. J., Volkert, W. A., and Hoffman, T. J. (2005). Radiolabeled peptide conjugates for targeting of the bombesin receptor superfamily subtypes. Nucl. Med. Biol. 32, 733-740.

Smyth, E. C., and Cunningham, D. (2012). Targeted Therapy for Gastric Cancer. Curr. Treat. Options Oncol. 13, 377-389.

Smyth, M. J., Dunn, G. P., and Schreiber, R. D. (2006). Cancer immunosurveillance and immunoediting: the roles of immunity in suppressing tumor development and shaping tumor immunogenicity. Adv. Immunol. 90, $1-50$.

Snelling, L., Miyamoto, C. T., Bender, H., Brady, L. W., Steplewski, Z., Class, R., et al. (1995). Epidermal growth factor receptor 425 monoclonal antibodies radiolabeled with iodine- 125 in the adjuvant treatment of highgrade astrocytomas. Hybridoma 14, 111-114.

Sofou, S., Thomas, J. L., Lin, H. Y., Mcdevitt, M. R., Scheinberg, D. A., and Sgouros, G. (2004). Engineered liposomes for potential alphaparticle therapy of metastatic cancer. J. Nucl. Med. 45, 253-260.

Sun, J., and Xie, G. (2011). Tissue distribution of intravenously administrated hydroxyapatite nanoparticles labeled with 125I. J. Nanosci. Nanotechnol. 11, 10996-11000.

Syed, R., Bomanji, J., Nagabhushan, N. Kayani, I., Groves, A., Waddington, W., et al. (2006). 186Re-HEDP in the treatment of patients with inoperable osteosarcoma. J. Nucl. Med. 47 1927-1935.

Talekar, M., Kendall, J., Denny, W., and Garg, S. (2011). Targeting of nanoparticles in cancer: drug delivery and diagnostics. Anticancer. Drugs 22, 949-962.

Tang, Q. S., Chen, D. Z., Xue, W. Q., Xiang, J. Y., Gong, Y. C. Zhang, L., et al. (2011). Preparation and biodistribution of 188Re-labeled folate conjugated human serum albumin magnetic cisplatin nanoparticles (188Re-folate-CDDP/HSA MNPs) in vivo. Int. J. Nanomed. 6, 3077-3085.

Tavangar, A., Tan, B., and Venkatakrishnan, K. (2011). Synthesis of three-dimensional calcium carbonate nanofibrous structure from eggshell using femtosecond laser ablation. J. Nanobiotechnol. 9, 1.

Teoh, M., Clark, C. H., Wood, K., Whitaker, S., and Nisbet, A. (2011). Volumetric modulated arc therapy: a review of current literature and clinical use in practice. Br. J. Radiol. 84, 967-996.

Tesniere, A., Schlemmer, F., Boige, V., Kepp, O., Martins, I., Ghiringhelli, F., et al. (2010). Immunogenic death of colon cancer cells treated with oxaliplatin. Oncogene 29, 482-491.

Ting, G., Chang, C. H., Wang, H. E., and Lee, T. W. (2010). Nanotargeted radionuclides for cancer nuclear imaging and internal radiotherapy. J. Biomed. Biotechnol. 2010, pii: 953537.

Torres-Garcia, E., Ferro-Flores, G., Arteaga De Murphy, C., CorreaGonzalez, L., and Pichardo-Romero, P. A. (2008). Biokinetics and dosimetry of 188Re-anti-CD20 in patients with non-Hodgkin's lymphoma: preliminary experience. Arch. Med. Res. 39, 100-109.

Trombetta, E. S., and Mellman, I. (2005). Cell biology of antigen processing in vitro and in vivo. Annu. Rev. Immunol. 23, 975-1028.

Tsai, C. C., Chang, C. H., Chen, L. C., Chang, Y. J., Lan, K. L., Wu, Y. H., et al. (2011). Biodistribution and pharmacokinetics of 188Re-liposomes and their comparative therapeutic efficacy with 5-fluorouracil in C26 colonic peritoneal carcinomatosis mice. Int. J. Nanomed. 6, 2607-2619.

Turtoi, A., Brown, I., Schlager, M., and Schneeweiss, F. H. (2010). Gene expression profile of human lymphocytes exposed to (211)At alpha particles. Radiat. Res. 174, 125-136.

Turtoi, A., and Schneeweiss, F. H. (2009). Effect of (211)At alphaparticle irradiation on expression of selected radiation responsive genes in human lymphocytes. Int. J. Radiat. Biol. 85, 403-412.

Uto, T., Akagi, T., Toyama, M., Nishi, Y., Shima, F., Akashi, M., et al. (2011a). Comparative activity of biodegradable nanoparticles with aluminum adjuvants: antigen uptake by dendritic cells and induction of immune response in mice. Immunol. Lett. 140 36-43.

Uto, T., Akagi, T., Yoshinaga, K., Toyama, M., Akashi, M., and Baba, M. (2011b). The induction of innate and adaptive immunity by biodegradable poly(gammaglutamic acid) nanoparticles via a TLR4 and MyD88 signaling pathway. Biomaterials 32, 5206-5212.

Uto, T., Wang, X., Sato, K., Haraguchi, M., Akagi, T., Akashi, M., etal. (2007). Targeting of antigen to dendritic cells with poly(gammaglutamic acid) nanoparticles induces antigen-specific humoral and cellular immunity. J. Immunol. 178, 29792986.

van Dodewaard-de Jong, J. M., De Klerk, J. M., Bloemendal, H. J., Van Bezooijen, B. P., De Haas, M. J., Wilson, R. H., etal. (2011). A phase I study of combined docetaxel and repeated high activity 186Re-HEDP in castration-resistant prostate cancer (CRPC) metastatic to bone (the TAXIUM trial). Eur. J. Nucl. Med. Mol. Imaging 38, 1990-1998.

Vanpouille-Box, C., Lacoeuille, F., Belloche, C., Lepareur, N., Lemaire, L., Lejeune, J. J., et al. (2011a). Tumor eradication in rat glioma and bypass of immunosuppressive barriers using internal radiation with (188)Re-lipid nanocapsules. Biomaterials 32, 67816790.

Vanpouille-Box, C., Lacoeuille, F., Roux, J., Aube, C., Garcion, E., Lepareur N., et al. (2011b). Lipid nanocapsules loaded with rhenium-188 reduce tumor progression in a rat hepatocellular carcinoma model. PLoS ONE 6, e16926. doi: 10.1371/journal.pone.0016926

Vesely, M. D., Kershaw, M. H., Schreiber, R. D., and Smyth, M. J. (2011). Natural innate and adaptive immunity to cancer. Annu. Rev. Immunol. 29, 235-271.

Vrignaud, S., Benoit, J. P., and Saulnier, P. (2011). Strategies for the nanoencapsulation of hydrophilic molecules in polymer-based nanoparticles. Biomaterials 32, 8593-8604.

Walsh, L., Morgia, M., Fyles, A., and Milosevic, M. (2011). Technological advances in radiotherapy for cervical cancer. Curr. Opin. Oncol. 23, 512-518.

Watts, C. (2004). The exogenous pathway for antigen presentation on major histocompatibility complex class II and CD1 molecules. Nat. Immunol. 5, 685-692.

Weiss, B., Schneider, M., Muys, L., Taetz, S., Neumann, D., Schaefer, U. F., et al. (2007). Coupling of biotin(poly(ethylene glycol))amine to poly (D,L-lactide-co-glycolide) nanoparticles for versatile surface modification. Bioconjug. Chem. 18, 1087-1094.

Weissleder, R., Kelly, K., Sun, E. Y., Shtatland, T., and Josephson, L. (2005). Cell-specific targeting of nanoparticles by multivalent attachment of small molecules. Nat. Biotechnol. 23, 1418-1423.

Wen, N., Walls, N., Kim, J., Jin, J. Y., Kim, S., Nurushev, T., et al. (2012). Clinical use of dual image-guided localization system for spine radiosurgery. Technol. Cancer Res. Treat. 11, 123-131.

Whiteside, T. L. (2008). The tumor microenvironment and its role in promoting tumor growth. Oncogene 27, 5904-5912.

Xu, Q., Liu, Y., Su, S., Li, W., Chen, C., and Wu, Y. (2012). Antitumor activity of paclitaxel through dual-targeting carrier of cyclic RGD and transferrin conjugated hyperbranched copolymer nanoparticles. Biomaterials 33, 1627-1639.

Yoncheva, K., Gomez, S., Campanero, M. A., Gamazo, C., and Irache, J. M. (2005). Bioadhesive properties of pegylated nanoparticles. Expert Opin. Drug Deliv. 2, 205-218.

Yoong, J., Michael, M., and Leong, T. (2011). Targeted therapies for gastric cancer: current status. Drugs 71, 1367-1384.

Yoshida, M., and Babensee, J. E. (2004). Poly(lactic-co-glycolic acid) enhances maturation of human monocyte-derived dendritic cells. $J$. Biomed. Mater. Res. A 71, 45-54. 
Yoshida, M., and Babensee, J. E. (2006). Differential effects of agarose and poly(lactic-co-glycolic acid) on dendritic cell maturation. J. Biomed. Mater. Res. A 79, 393-408.

Yoshida, M., Mata, J., and Babensee, J. E. (2007). Effect of poly(lactic-coglycolic acid) contact on maturation of murine bone marrow-derived dendritic cells. J. Biomed. Mater. Res. A 80, 7-12.

Yu, C. X., and Tang, G. (2011). Intensitymodulated arc therapy: principles, technologies and clinical implementation. Phys. Med. Biol. 56, R31-R54.

Zhan, C., Meng, Q., Li, Q., Feng, L., Zhu, J., and Lu, W. (2012).
Cyclic RGD-polyethylene glycolpolyethylenimine for intracranial glioblastoma-targeted gene delivery. Chem. Asian J. 7, 91-96.

Zitvogel, L., Apetoh, L., Ghiringhelli, F. Andre, F., Tesniere, A., and Kroemer, G. (2008). The anticancer immune response: indispensable for therapeutic success? J. Clin. Invest. 118, 1991-2001.

Zitvogel, L., Kepp, O., Senovilla, L., Menger, L., Chaput, N., and Kroemer, G. (2010). Immunogenic tumor cell death for optimal anticancer therapy: the calreticulin exposure pathway. Clin. Cancer Res. 16, 3100-3104.
Zitvogel, L., Tesniere, A., and Kroemer, G. (2006). Cancer despite immunosurveillance: immunoselection and immunosubversion. Nat. Rev. Immunol. 6, 715-727.

Conflict of Interest Statement: The authors declare that the research was conducted in the absence of any commercial or financial relationships that could be construed as a potential conflict of interest.

Received: 09 July 2012; accepted: 20 September 2012; published online: 10 October 2012.
Citation: Vanpouille-Box $C$ and Hindré $F$ (2012) Nanovectorized radiotherapy: a new strategy to induce anti-tumor immunity. Front. Oncol. 2:136. doi: 10.3389/fonc.2012.00136

This article was submitted to Frontiers in Radiation Oncology, a specialty of Frontiers in Oncology.

Copyright (c) 2012 Vanpouille-Box and Hindré. This is an open-access article distributed under the terms of the Creative Commons Attribution License, which permits use, distribution and reproduction in other forums, provided the original authors and source are credited and subject to any copyright notices concerning any third-party graphics etc. 